\title{
Disparities in Nursing of Multiple Sclerosis Patients - Results of a European Nurse Survey
}

\author{
Hans-Peter Hartung, ${ }^{1}$ Vicki Matthews, ${ }^{2}$ Amy Perrin Ross, ${ }^{3}$ Dorothea Pitschnau-Michel, ${ }^{4}$ Christoph Thalheim $^{5}$ and \\ Nicki Ward-Abel ${ }^{6}$ on behalf of the Multiple Sclerosis-Nurse Empowering Education (MS-NEED) Study Group
}

\begin{abstract}
1. Professor, and Chair, Department of Neurology, Neurology Clinic, Heinrich-Heine University, Düsseldorf; 2. MS Specialist Nurse Advisor, MS Trust and Clinical Nurse Specialist, Southampton University Hospitals Trust; 3. MS Specialist Nurse, Department of Neurosciences, Loyola University, Chicago; 4. Secretary General, German National MS Society and Board Member, European MS Platform; 5. Secretary General, European MS Platform; 6. Specialist MS Lecturer Practitioner, Birmingham City University, University Hospital
\end{abstract}

\begin{abstract}
Nurses play a critical role in caring for patients with multiple sclerosis (MS). The Multiple Sclerosis-Nurse Empowering Education (MS-NEED): European Survey was conducted to understand the role of nurses in MS and the provision of care across Europe. The survey focused on four key areas: clinical practice, advocacy, research and publication, and training and education. A total of 280 nurses were included from the UK, Germany, Italy, Poland, Finland and the Czech Republic. All participants were nurses actively working with MS patients. The role of the nurse in MS is diverse and varies substantially across Europe, leading to inequalities in patient care. A European consensus to define the roles and responsibilities of the MS nurse would facilitate consistency of care across all countries and help to achieve the best possible outcome for patients with MS in Europe.
\end{abstract}

\section{Keywords}

Multiple sclerosis, nursing, nurse, treatment, MS-Nurse Empowering Education (MS-NEED), specialist role

\begin{abstract}
Disclosure: Hans-Peter Hartung has received honoraria - with the approval of the Rector of Heinrich-Heine-University - for consulting, membership of steering committees and advisory boards and speaking at symposia from Bayer Healthcare, Biogen Idec, Genzyme, Merck Serono, Novartis Pharma AG, Teva and sanofi-aventis. Vicki Matthews has served on the Advisory Board as an Expert Consultant and Speaker for Merck Serono, Biogen Idec and Novartis Pharma AG, and all honoraria is donated to the MS Trust. Amy Perrin Ross has served on the Advisory Board, as a Consultant or a Speaker for Bayer Healthcare, EMD Serono, Pfizer Inc., Teva Neuroscience, Novartis Pharma AG, Genzyme, Acorda and Questcor. Nicki Ward-Abel has served on the advisory board, as a consultant or a speaker, for Bayer Schering, Merck Serono, Teva Neuroscience, Biogen Idec and Novartis Pharma AG. Dorothea Pitschnau-Michel and Christoph Thalheim have no conflicts of interest to declare.

Acknowledgements: The Multiple Sclerosis-Nurse Empowering Education (MS-NEED) study group includes the European MS Platform (EMSP), the International Organization of MS Nurses (IOMSN) and Rehabilitation in MS (RIMS). The MS-NEED: European Survey was supported by an unrestricted educational grant from Novartis Pharma AG. The acceptance of this grant does not constitute endorsement by the EMSP of any of Novartis' products. The EMSP does not approve, endorse or recommend any specific product or therapy but provides information to assist individuals in making their own decisions. The MS-NEED: European Survey was fielded by Adelphi International Research. Editorial support for the preparation of this manuscript was funded by the EMSP.

Received: 28 January 2011 Accepted: 14 March 2011 Citation: European Neurological Review, 2011;6(2):106-9 DOI:10.17925/ENR.2011.06.02.106

Correspondence: Hans-Peter Hartung, Neurology Clinic, Heinrich-Heine University, Moorenstrasse 5, 40225 Düsseldorf, Germany. E: hans-peter.hartung@uni-duesseldorf.de
\end{abstract}

Multiple sclerosis (MS) is a chronic autoimmune disease resulting in demyelination and axonal loss in the central nervous system (CNS). This may lead to significant neurological deficits and physical disability including blurred vision, speech problems, loss of balance and coordination, pain and fatigue. ${ }^{1-3}$ According to the natural history of the disease, within 20 years of diagnosis approximately $50 \%$ of patients will require the use of a wheelchair. ${ }^{4}$ MS represents a significant burden on the quality of life of patients, including problems at work and in personal relationships. ${ }^{3,5,6}$

It is estimated that up to 2.5 million people across the world are affected by $\mathrm{MS}^{7}$ including nearly half a million people in the EU. ${ }^{2}$ Most patients are diagnosed between 20 and 40 years of age, ${ }^{3}$ with three women affected for every two men. ${ }^{2}$

Currently, there is no cure for MS, although the introduction of drugs in the 1990s aimed at modifying the course of the disease has made it an increasingly treatable neurological condition. However, there is no doubt that the main goal of MS management continues to be improving patient quality of life by managing relapses, treating symptoms ${ }^{7}$ and offering timely ongoing support, information and advice to all those affected. ${ }^{8}$

There are many complex challenges when caring for patients with MS and management strategies must address patients' medical, social, vocational, emotional and educational needs. ${ }^{\text {Therefore, it is }}$ important that patients with MS have access to co-ordinated care from a specialised multidisciplinary team (MDT). ${ }^{2,9}$ As a part of this team, the nurse has emerged as a key player in the provision of information, support and advice to patients with MS from the time of diagnosis and throughout the disease trajectory, providing a holistic, collaborative and coordinated approach to treatment. ${ }^{10}$ However, there is a need for greater understanding and awareness of the role of nurses and to identify best practice in order to improve patient access to care and optimise quality of life. 
Figure 1: The Involvement of Nurses in Managing Other Health Conditions Associated with Multiple Sclerosis

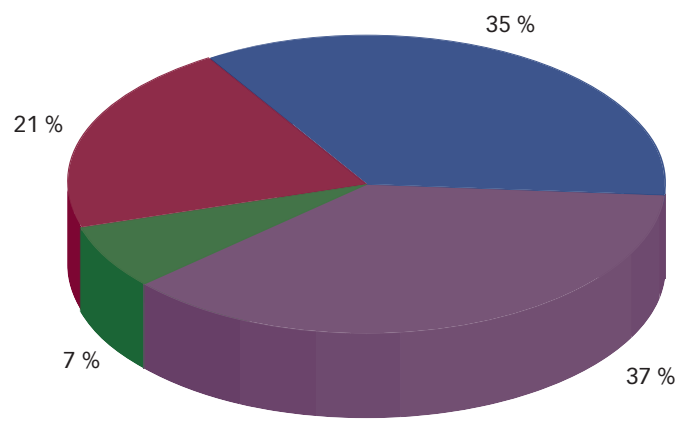

Very involved Involved Somewhat involved

Not involved

Multiple Sclerosis-Nurse Empowering Education (MS-NEED) European survey showed that the role of the MS nurse is expanding beyond the traditional responsibilities and that this may be owing to changes in clinical practice and patient engagement.

Figure 2: Nurses are Key Advocates in Helping Patients Gain Access to New Treatments and Other Services (e.g. Rehabilitation Services)
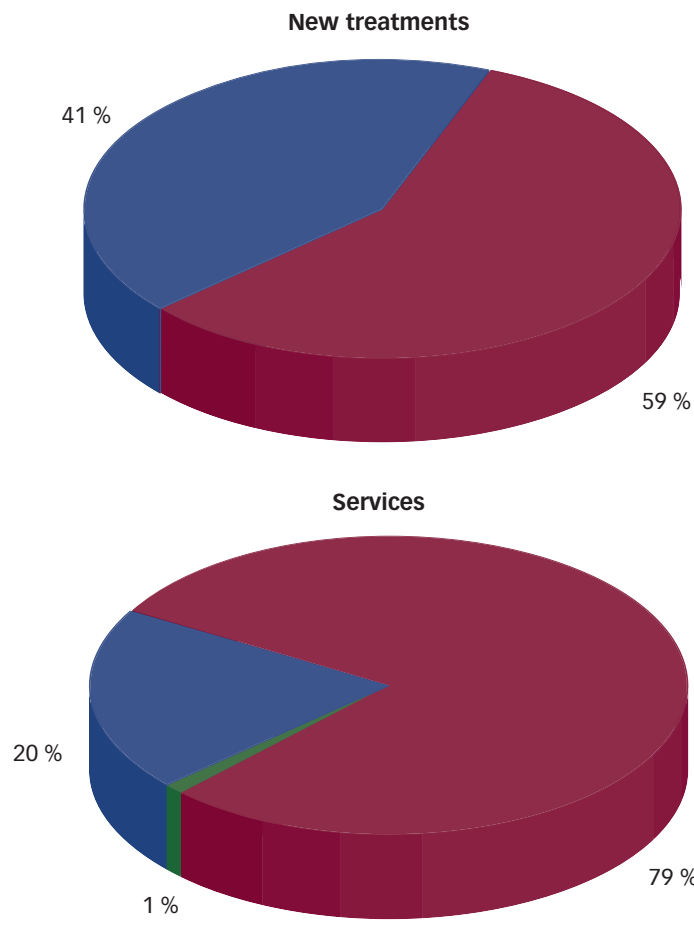

Yes

No

N/A

The extent to which nurses help people with multiple sclerosis (MS) gain access to new treatment varies substantially across Europe.

\section{A European Survey of \\ Current Practice and Future Needs}

The Multiple Sclerosis-Nurse Empowering Education (MS-NEED): European Survey led by the European Multiple Sclerosis Platform (EMSP) in collaboration with the International Organization of MS Nurses (IOMSN) and Rehabilitation in MS (RIMS) centres was conducted to understand and raise awareness of the roles of nurses in MS and the provision of care across Europe. Furthermore, the survey aimed to identify areas for improvement and best practice and assess the need for comprehensive nurse services across Europe.
Figure 3: Areas Where Nurses Often Offer Advice and Education

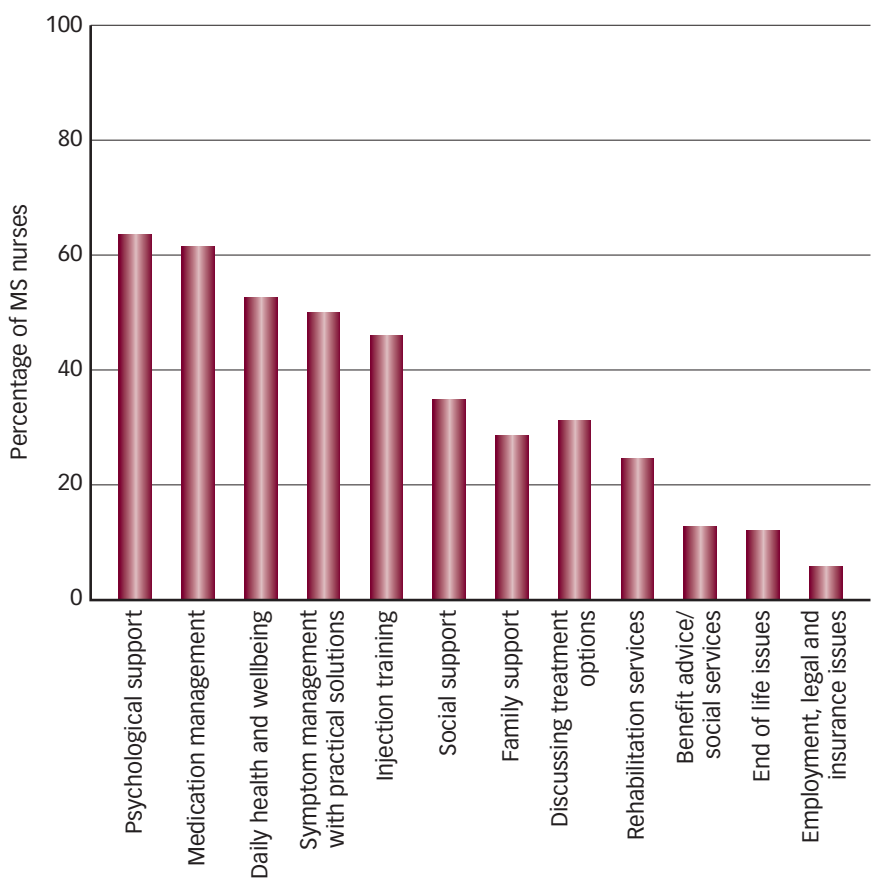

MS = multiple sclerosis

Figure 4: Nurses' Response to the Question 'Do You Feel the Standards of Multiple Sclerosis Care are Well Maintained in your Country?'

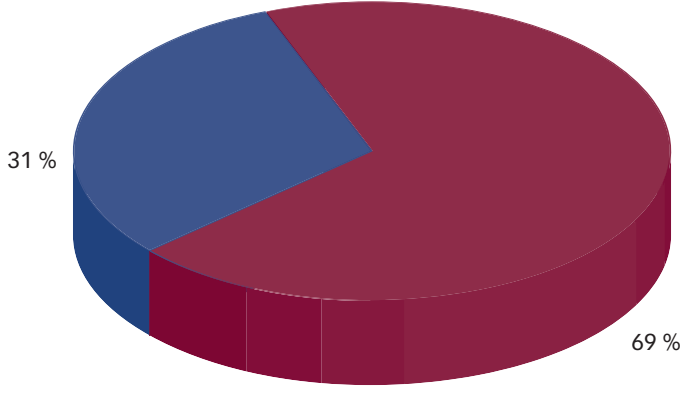

\begin{tabular}{ll}
\hline & No \\
Why yes? & Why no? \\
- Information/data/education & $\bullet$ Inadequate treatment \\
- Better healthcare quality/ & Inadequate information/ \\
improved quality of life & data/education \\
for patients with & - Inadequate financial \\
multiple sclerosis & support/inadequate \\
- Compliance with guidelines & economic assistance \\
- Availability of drugs/everyone & - Inadequate guidelines/ \\
has access to therapy & clinical standards
\end{tabular}

The survey comprised a 35-minute, 60-item questionnaire focusing on four key areas: clinical practice, advocacy, training and education and research and publication. It was conducted in six European countries: the UK, Germany, Italy, Poland, Finland and the Czech Republic. A six-item screening questionnaire was used to ensure that all participants were nurses actively working with MS patients. As such, participants in the UK and the Czech Republic were required to be specialist MS nurses (where this specific role is recognised). Nurses from Germany, Italy and Poland were required to spend $\geq 30 \%$ of their time with MS patients ( $\geq 25 \%$ for nurses in Finland) and to have been 


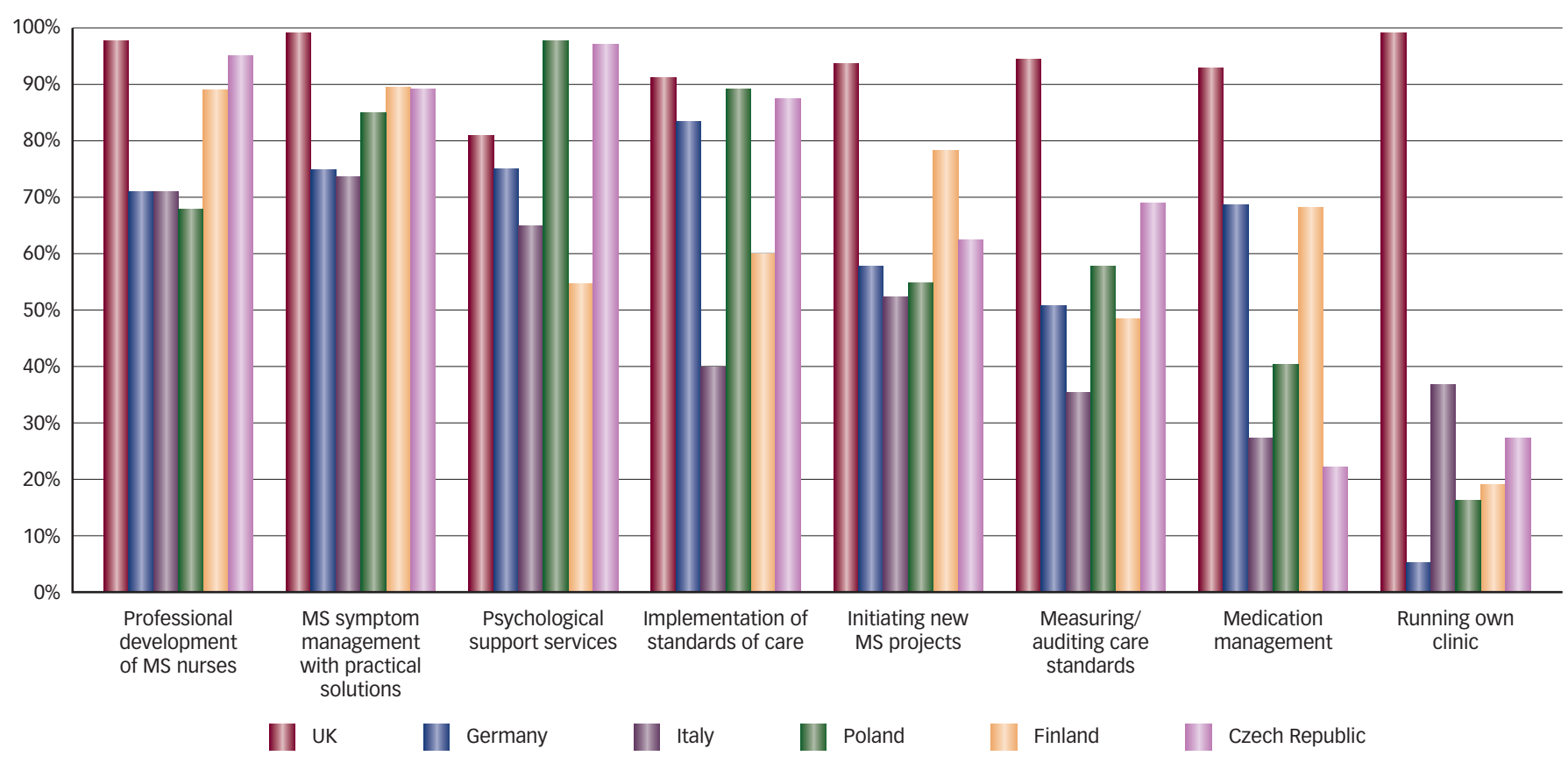

Multiple sclerosis (MS) nurses feel that specialist nurses in their country are able to lead in a number of areas of MS care, including professional development, symptom management and psychological support.

working with MS patients for more than one year. None of the participants of the survey had been involved in any market research on MS patients during the previous three months. All data were collected using the Computer-assisted Telephone Interviewing (CATI) method.

Between October and November 2009, 280 nurses participated in the MS-NEED: European Survey; 50 nurses were recruited from each of the European countries except for the Czech Republic, where 30 nurses were surveyed.

\section{Substantial Disparities in the Role of Multiple Sclerosis Nurses Across Europe and a Need to Standardise Clinical Practice}

Outcomes from the MS-NEED: European survey show that the support nurses provide to patients with MS varies substantially across Europe. Nurses in the UK are more involved in patient care, including providing their MS patients with advice and literature and assisting treatment decision-making and outlining available treatment options than the European average, but they are less involved in injection training. This is in contrast to nurses in Finland, who are more involved in injection training but less so in outlining available treatment options. Similarly, nurses in the Czech Republic and Italy place a greater emphasis on injection training but less on treatment decision-making and outlining available treatment options than their European counterparts.

Overall, the results suggest that there are disparities in standards of nursing across Europe. Contributing to this already diverse and varied role is the fact that more than half of nurses (56\%) are either 'very involved' or 'involved' in managing other health conditions associated with MS (see Figure 1). In order to avoid inequalities in patient care, it is important to standardise nursing across Europe and to share best practice. Indeed, nurses already have a shared appreciation of the most important aspects of their role, including tailoring support and information for patients, managing symptoms, working within an MDT and prescribing and managing medication. However, there is a need for a more formal approach that consolidates existing national frameworks to define a consensus on the roles and responsibilities of the MS nurse in Europe.

\section{Nurse Advocacy Varies Across Europe}

Nurses act as advocates on behalf of patients in accessing services that they consider to be important as part of MS patient care, including access to new treatments and clinical trials, and other services (e.g. rehabilitation services; see Figure 2). However, disparities in advocacy exist across Europe. Nurses who are most involved in helping patients to access new treatments and clinical trials are those from the UK and Germany. Overall, $45 \%$ of nurses are 'involved' or 'very involved' in helping patients with MS to gain reimbursement for new treatment. Nurses in the UK and Finland are most involved in helping patients to access other services, such as rehabilitation services, compared with the European average. Advice on employment, legal and insurance issues is considered to be less important by around half of all nurses. Of these issues, nurses are more likely to offer advice on employment than legal or insurance matters. Nurses in Finland and the UK were more likely to offer employment advice compared with other European countries.

Alongside results showing disparities in the roles and responsibilities of MS nurses across Europe, the MS NEED: European Survey shows that patient access to care and advice can vary from one country to another. Therefore, it is important to establish and share best practice and build collaborative expertise between clinics across Europe to ensure that patients are able to receive the most appropriate treatment and services.

\section{Nurses Feel Qualified to Manage Patients with} Multiple Sclerosis but Additional Training is Required Despite disparities in nursing standards, most nurses in Europe feel qualified to provide specialist advice and education for patients with MS. The majority of nurses often provide injection training, psychological 
support, medication management, advice on daily health and wellbeing and management of symptoms (see Figure 3).

Overall, $31 \%$ of nurses in Europe feel that standards of MS care are not well maintained in their country (see Figure 4). This is mainly owing to inadequate treatment, information and education, which highlights the need for a more structured approach to training across Europe. Indeed, most nurses believe that it is very important that their role evolves within the next five years, particularly in the areas of overall service development, providing support/information to patients and their carers, caring for patients with advanced MS, managing symptoms and advising and educating other healthcare professionals.

Currently, there is a lack of consensus among nurses about how their role is perceived by the MDT. Most nurses see themselves as a patient advisor, an intermediary between the patient and MDT or a leader of patient care. Nurses in the UK are significantly more likely to feel like leaders than nurses of other European countries. Encouragingly, nurses feel that they are able to lead in a number of areas of care with the potential for improvement in key areas including measuring and auditing care standards (see Figure 5). In order to provide nurses with the opportunity to develop in their role and to avoid inequalities in patient management across Europe, it is important to recognise nursing in MS as a speciality within Europe and to provide a consensus approach to ongoing training and development.

\section{Sharing Best Practice Provides an Important Opportunity for Nurses to Improve Patient Care} Nurses across Europe feel that training and education would be beneficial and help them to learn new skills. In this regard, $82 \%$ of nurses feel that sharing best practice would be beneficial, as well as training and education on psychosocial aspects of chronic illness (76\%), implementing guidelines (73\%), latest scientific developments (70\%) and new ways of delivering patient care (70 \%). Nurses are also interested in expanding their existing skills, especially symptom management, overall service development, health assessment and how to educate others.

Overall, $80 \%$ of nurses have attended MS-specific courses and conferences, although less so in Poland and the Czech Republic. Most training courses are usually provided by local MS societies (74\%) or the pharmaceutical industry (59\%). On average, European nurses attend three MS-specific courses and conferences per year.

However, $21 \%$ of nurses feel they have not received adequate training and education to support them in their day-to-day role in treating MS. When exploring reasons for this, nurses cited a lack of training courses, inadequate information and time constraints. Taking this into account, there is a clear and immediate need for ongoing and certified training of nurses across Europe in order to maintain a high standard of care in patients with MS.

\section{Nurses Want to be Informed of New Scientific Developments but Few are Actively Involved in Research}

Nurses are keen to remain up-to-date in the field of MS by obtaining information through nurse meetings, journal publications, newsletters, networking events and online social media, with no preferred method of delivery between or within countries. In addition, nurses would like best practice to be shared in a similar way. For $61 \%$ of respondents MS research has changed clinical practice by providing access to new treatments, better healthcare and information. In total, $70 \%$ of nurses are keen to share this information and research with patients and families, especially in the UK and Finland.

Despite wanting to keep up-to-date with the latest research in MS, only $39 \%$ of nurses have undertaken research in the past. This is because they do not have the opportunity or the time, or have never been asked. For others, no research is being conducted at their centre. At the time of the survey, only $19 \%$ of nurses were currently involved in research activities, most commonly clinical trials and clinical research. Overall, only $8 \%$ of nurses have ever published an article on MS.

\section{Standardising the Role of Multiple Sclerosis Nurses Can Improve Patient Outcomes Across Europe}

Nurses play a critical role in MS patient care and the results of the MS-NEED: European survey show that the nurse's role is diverse and varies substantially across Europe. Furthermore, patient access to treatment and services can vary from one country to another, leading to inequalities in patient care. Overall, nearly one-third of nurses feel that standards of MS care are not well maintained in their country and one-fifth lack sufficient training to perform their day-to-day role in MS. However, it is encouraging that the majority of nurses feel that it is important that their role develops over the next five years. Indeed, nurses feel that ongoing training and education is important for their professional development, especially sharing best practice.

In order to avoid inequalities in patient care and to provide nurses with the opportunity to develop in their role, it is important to recognise nursing in MS as a speciality within Europe, to standardise and benchmark training and to share best practice.

Based on the results of survey, the MS-NEED study group recommends consolidating existing national tools in order to develop a European consensus framework to define the role and responsibilities of the MS nurse, which would aid alignment in the consistency of care across all countries and facilitate the best possible outcome for people with MS in Europe. In addition, this would need to be supported by a European MS Nurse network affiliated with an international professional organisation to share best practice and move MS nursing forward.
1. EMSP, What is MS?, 2010. Available at: www.ms-in-europe.org (accessed October 2010).

EMSP, MS - fact sheet, 2010. Available at: www.ms-in-europe.org (accessed October 2010)

3. Isaksson AK, Ahlstrom G, Gunnarsson LG, Quality of life and impairment in patients with multiple sclerosis, I Neurol impairment in patients with multiple scl
Neurosurg Psychiatry, 2005;76(1):64-9.

4. Weinshenker BG, et al., The natural history of multiple sclerosis: a geographically based study. I. Clinical course and disability, Brain, 1989;112(Pt 1):133-46.

5. Forbes A, et al., Health problems and health-related quality of life in people with multiple sclerosis, Clin Rehabil,

2006;20(1):67-78

6. Ford $\mathrm{HL}$, et al., Health status and quality of life of people with multiple sclerosis, Disabil Rehabil, 2001;23(12):516-21.

. Huynh T, The multiple sclerosis market, Nat Rev Drug Discov,
2010;9(10):759-60.

8. Burgess M, Shedding greater light on the natural history and prevalence of multiple sclerosis, Brit J Neurosci Nursing, 2010;6(1):7-11.

9. Harper J, Comprehensive Care in Multiple Sclerosis - A Patient-centred Approach, Eur Neurol Rev, 2009:3(2):72-4. . Patient-centred Approach, Eur Nit with people with multiple sclerosis, I Clin Nurs, 2009;18(18):2635-48.
wille 